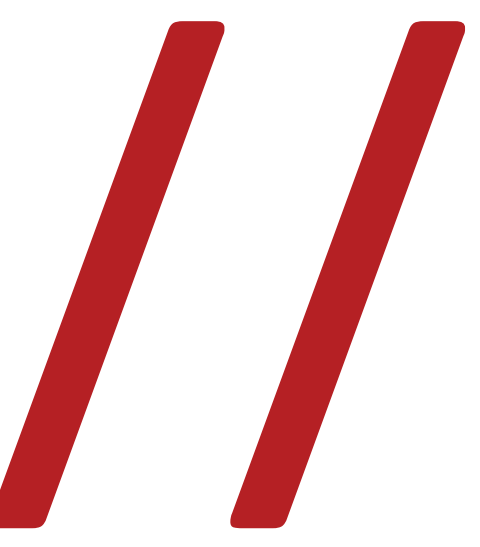

\title{
Atributos de séries dramáticas de sucesso e engajamento da audiência
}

Successful drama TV series features and audience engagement

Sílvio Antonio Luiz Anaz ${ }^{1}$

\footnotetext{
${ }^{1}$ Pesquisador de pós-doutorado em Meios e Processos Audiovisuais na Escola de Comunicações e Artes da Universidade de São Paulo (ECAUSP). Doutor em Comunicação e Semiótica pela Pontifícia Universidade Católica (PUC-SP). E-mail: silvioanaz@hotmail.com
} 
Resumo: parte das séries dramáticas da TV caracteriza-se pela hibridação dos formatos episódico e serial, universo expandido (transmídia), engajamento da audiência e arcos longos que aprofundam as características dos personagens. Este artigo analisa esse fenômeno a partir da identificação das principais especificidades dos processos contemporâneos de criação e de fruição das séries televisivas para, em seguida, mapear e descrever os recursos que têm se destacado e contribuído para o seu êxito. Os resultados mostram a importância do papel do showrunner, da lógica de produção e consumo dos canais por assinatura e do uso de recursos narrativos desafiadores para a audiência no sucesso dessas séries.

Palavras-chave: série de TV; narrativa complexa; série dramática; engajamento da audiência; processo criativo.

Abstract: some contemporary drama TV series are characterized by hybrid format (serial and episodic), expanded universe (transmedia), audience engagement, and long arcs that elaborate on personage's characteristics. This paper analyzes this phenomenon in two steps: first, it establishes the main specificities in contemporary creation and fruition processes of TV series; second, it maps and delineates the outstanding resources that have contributed to their success. The results indicate the importance of the role of showrunner, the logic of production and consumption in pay TV, and the use of challenging narrative resources for audience in the successful contemporary drama TV series.

Keywords: TV series; complex narrative; drama TV series; audience engagement; creative process. 


\section{Introdução ${ }^{2}$}

Um dos mais importantes fenômenos na indústria do audiovisual, a partir principalmente dos anos 2000, é o sucesso de um conjunto de séries dramáticas para a TV que têm sido classificadas como narrativas complexas (MITTEL, 2015) ou narrativas cinematográficas longas (KALLAS, 2016), tais as aproximações que elas fazem com a linguagem e a estética cinematográficas. Mittell (2012; 2015), Jenkins (2008) e Kallas (2016) apontam algumas especificidades dessas narrativas televisivas: hibridação dos formatos episódico e serial, universo expandido (transmidiático), engajamento da audiência e arcos longos que resultam no aprofundamento das características dos personagens.

Um ponto em comum na abordagem de Mittell, Jenkins e Kallas é que eles trazem para a reflexão as dinâmicas que compõem os processos de criação e de produção das séries, as lógicas que comandam os negócios da indústria do audiovisual e o papel ativo das audiências, elementos da realidade de produção e fruição das séries de TV que muitas vezes têm pouca relevância, ou que estão até mesmo ausentes, nos estudos dos fenômenos televisivos, especialmente naqueles que se fundamentam nas teorias fílmicas, na semiótica, na teoria crítica e na narratologia.

Dar relevância a esses elementos é importante à medida que os modos de produção e fruição da série dramática televisiva se interconectam e têm particularidades que os fazem significativamente diferentes dos modos de produção e fruição de outros produtos culturais, até mesmo dos cinematográficos.

\section{Especificidades nos processos de criação e de fruição}

Se a concepção de narrativas televisivas é evidentemente distinta da de outras linguagens (literatura, teatro etc.), há, no entanto, importantes semelhanças entre os processos atuais de criação de séries produzidas originalmente para a televisão (e multiplataformas) ${ }^{3}$ e os de filmes para o cinema. Em ambos os casos, os processos criativos são hierarquizados, obedecem à lógica de negócios que rege a indústria do audiovisual e são colaborativos, pois envolvem diversos agentes, como

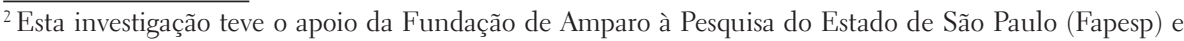
da Coordenação de Aperfeiçoamento de Pessoal de Nível Superior (Capes) (Processo 2014/13330-1). O autor é responsável pelas opiniões, hipóteses, conclusões e recomendações expressas neste artigo, e elas não refletem necessariamente os pontos de vista da Fapesp e da Capes.

${ }^{3}$ Incluem-se aqui as plataformas e tecnologias que essas séries também buscam atender, como streaming, vídeo on-demand, apps, dvds, blu-rays, e suas diversas telas: televisão, smartphones, computadores, tablets etc.
} 
roteiristas, produtores, diretores, atores, editores e executivos, que contribuem em diferentes níveis para a versão final do produto. Além disso, principalmente a partir dos anos 2000, as produções de séries televisivas passaram a compartilhar elencos, diretores e roteiristas consagrados com as produções cinematográficas, têm recebido dotações orçamentárias nos mesmos patamares de muitos blockbusters e usado tantos recursos tecnológicos quanto as grandes produções para o cinema, como as imagens geradas por computador (CGI, na sigla em inglês).

Mas há também diferenças significativas entre a criação de uma série para a TV e de um filme destinado originalmente ao cinema. As principais são relativas aos papeis assumidos pelos diretores e roteiristas e aos fluxos de criação, tomada de decisões corporativas e produção em cada um desses processos.

Enquanto no cinema o diretor do filme é o principal responsável pelo processo de criação, encarregado de todas as etapas, mesmo quando não participa diretamente delas - o que Mittell (2015, p. 88) classifica como autoria por responsabilidade (authorship by responsability) -, no processo de criação de séries para a TV, o papel principal cabe ao roteirista e/ou criador da série. No modelo da TV norte-americana (normalmente, paradigma para os modelos adotados por vários países, inclusive o Brasil), o roteirista-criador assume o controle desde a criação até a edição final, sobrepondo-se aos diretores dos episódios e ocupando uma posição de liderança e gerenciamento do projeto, incluindo questões orçamentárias, de cronograma e a supervisão da sala de roteiristas ${ }^{4}$ - o que Mittell (2015, p. 88) classifica como autoria por gerenciamento (authorship by management). Tal posição do roteirista-criador na TV norte-americana tem sido denominada informalmente de showrunner.

No âmbito dos fluxos dos processos de criação e produção das obras cinematográficas e das séries televisivas, além do impacto que os diferentes papeis assumidos por diretores e roteiristas têm em cada situação, há também diferenças nas instâncias envolvidas e na dinâmica da produção, conforme o demonstrado nos diagramas a seguir (Figuras 1 e 2).

\footnotetext{
${ }^{4}$ A sala de roteiristas (writers' room) é o espaço em que se reúnem showrunner, roteiristas, produtores e editores para discutir e revisar tramas, arcos, prazos e outros elementos que compõem os processos de criação e produção de uma série televisiva. O método adotado, geralmente, é o de discussão de cada episódio em detalhes antes do roteirista designado trabalhar nele. Na dinâmica da sala, os primeiros rascunhos são revisados pelo showrunner e seguem para aprovações do estúdio e da emissora.
} 


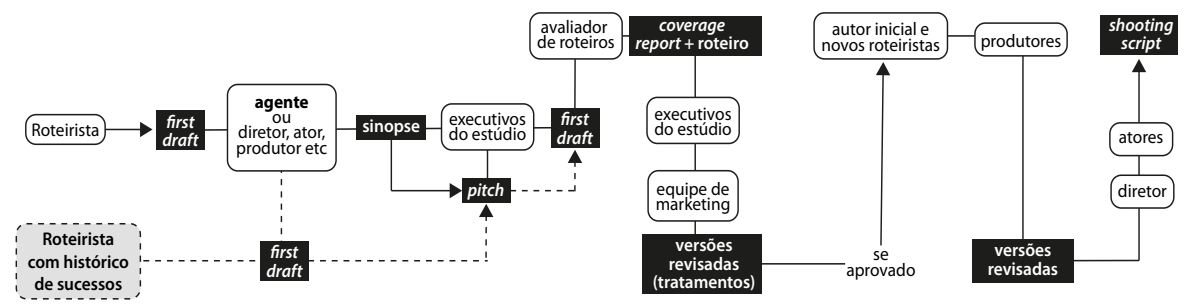

Figura 1: Processo de criação e tomada de decisões na produção de filme para cinema Fonte: Elaborada pelo autor.

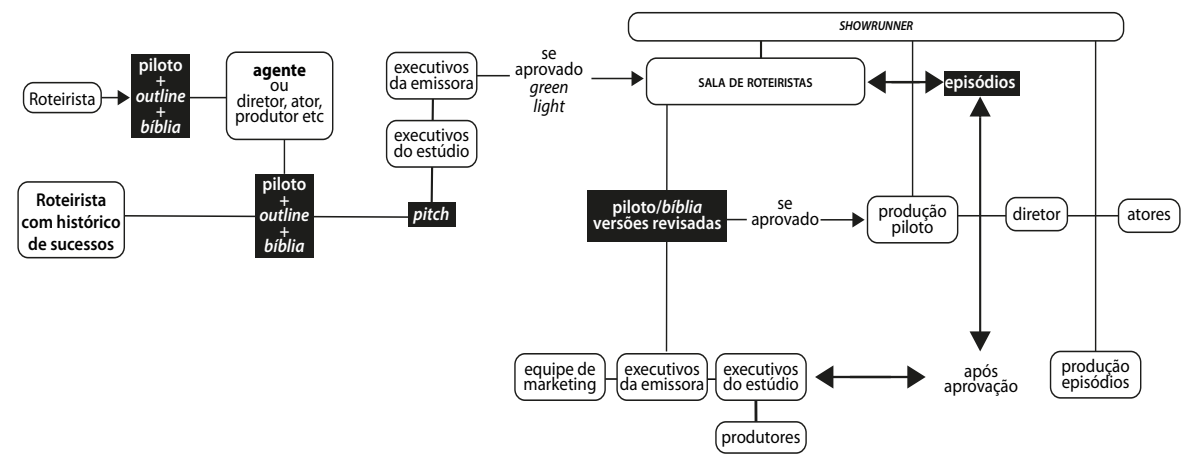

Figura 2: Processo de criação e tomada de decisões na produção de série de TV Fonte: Elaborada pelo autor.

Os diagramas mostram que enquanto no cinema (Figura 1) o processo de tomada de decisões envolve criadores (roteiristas, diretores etc.) e executivos do estúdio ou produtora, na televisão (Figura 2) há mais uma parte envolvida: a dos executivos da rede ou emissora que veiculará a série, o que introduz uma nova instância para aprovação dos roteiros. Outra diferença importante diz respeito à dinâmica de produção e aprovação dos roteiros. Ainda que em ambas as situações os roteiros sigam sujeitos a modificações até o momento da filmagem, nas séries televisivas, normalmente, o showrunner tem maior controle sobre eles e tem também de lidar com roteiros em diferentes estágios ao mesmo tempo: alguns sendo escritos pela equipe da sala de roteiristas, outros em processo de revisão após passarem pelo crivo dos executivos do estúdio e da emissora e outros em processo de filmagem e edição - situação esta que não ocorre na dinâmica do fluxo de criação e produção no cinema.

Ainda no âmbito da criação, as séries dramáticas televisivas, em função da duração alongada da narrativa, oferecem aos seus idealizadores e roteiristas a 
possibilidade de se aprofundarem na construção das características psicológicas e comportamentais dos personagens e de desenvolverem mais tramas paralelas e intrincadas do que, normalmente, um filme para o cinema permite.

Já no âmbito da recepção, quando comparada a fruição de um filme no cinema e de uma série na TV, além da questão relacionada ao maior tempo de duração que dá à série televisiva maior potencial para apresentar mais personagens e tramas intercaladas de forma aprofundada, há condições ambientais e tecnológicas que precisam ser consideradas. Enquanto o cinema oferece uma ambientação imersiva que favorece o foco do espectador na narrativa, a série televisiva é consumida em ambientes e dispositivos (residência, computador, smartphone) em que o espectador fica mais sujeito à dispersão, por conta de interferências ambientais, e também ao uso de múltiplas telas, que podem ampliar sua compreensão do que está sendo assistido, por meio de pesquisa de informações que complementem ou esclareçam aquelas presentes na narrativa. Deve-se considerar também que eventuais desvios na atenção do telespectador podem ser compensados em função dos recursos tecnológicos que possibilitam rever cenas e episódios - a disponibilidade de tecnologias de reprodução audiovisual doméstica (dvd, blu-ray, gravador digital etc.) e streaming possibilita tanto às produções originais para cinema como as para TV serem revistas pela audiência.

Em síntese, apesar das similaridades, os processos de criação e fruição das séries televisivas se distinguem dos de filmes para o cinema por apresentarem:

- instância adicional no processo de tomada de decisões corporativas: no cinema, o processo de tomada de decisão envolve criadores e executivos da produtora (e/ou estúdio); na TV, pode envolver criadores e executivos da produtora (e/ou estúdio) e da emissora5;

- showrunner com maior controle dos processos de criação e produção: no cinema, quem cria a narrativa (roteirista) tem pouca participação sobre os processos de produção e de decisões criativas, cuja responsabilidade fica normalmente a cargo do diretor - exceto quando o roteirista também é o diretor; na TV, o roteirista principal e/ou idealizador da narrativa assume geralmente a função de gerenciamento do processo criativo e de produção (na função de showrunner), com mais autonomia e autoridade do que os diretores dos episódios;

\footnotetext{
${ }^{5}$ A participação dos estúdios é mais comum no modelo norte-americano, uma vez que Universal, Disney, Fox, Paramount e Sony/Columbia são também players importantes na produção televisiva nos EUA.
} 
- tempo narrativo longo, que possibilita adensar tramas e personagens: no cinema, há uma limitação temporal mais rígida, para viabilizar comercialmente a exibição da película em grandes circuitos; na TV, a possibilidade de compor a narrativa a partir de vários episódios e temporadas amplia as possibilidades dos roteiristas de usar múltiplos protagonistas e tramas e aprofundar as características psicológicas dos personagens e a problematização das intrigas;

- fruição concorrida e complementar das narrativas: no cinema, a ambientação leva a audiência a focar na exibição da narrativa audiovisual por meio de um processo imersivo; nas séries exibidas na TV e outras telas (computador, tablet, smartphone etc.), a ambientação pode levar a um grau elevado de distração da audiência; por outro lado, o uso de múltiplas telas o que, normalmente, não é viável no cinema - possibilita ao telespectador ampliar o universo informacional sobre a narrativa.

Além das particularidades em relação à produção e à fruição, algumas das séries dramáticas contemporâneas desenvolveram características específicas no formato e no conteúdo. Características que as tornam tão distintas a ponto de alguns estudiosos como Mittell (2012, 2015) e Dunleavy (2018) as classificarem como séries ou narrativas complexas. Essa complexidade é, na avaliação desses pesquisadores, o resultado de estratégias narrativas adotadas pelos criadores das séries.

\section{Complexidade e estratégias narrativas}

A serialização é uma das estratégias narrativas que caracterizam uma parte significativa do conjunto de séries dramáticas contemporâneas bem-sucedidas. Essencial para a construção de tramas intrincadas e personagens com profundidade psicológica, dado que essas qualidades demandam arcos narrativos longos, a serialização é, na avaliação de Mittell, fator sine qua non para o desenvolvimento de narrativas complexas:

Em seu nível mais básico, [a complexidade narrativa] é uma redefinição de formas episódicas sob a influência da narração em série - não é necessariamente uma fusão completa dos formatos episódicos e seriados, mas um equilíbrio volátil. Recusando a necessidade de fechamento da trama em cada episódio, que caracteriza o formato episódico convencional, a complexidade narrativa privilegia estórias com continuidade e passando por diversos gêneros. (2012, p. 36) 
É preciso ressaltar que, para Mittell, a complexidade não significa necessariamente uma valorização positiva da narrativa televisiva:

Complexidade e valor não se implicam mutuamente pessoalmente, prefiro assistir a programas convencionais de alta qualidade como Dick Van Dyke Show e Everybody Loves Raymond do que a 24 Horas, que é narrativamente complexo mas confuso conceitualmente e logicamente enlouquecedor. No entanto, a complexidade narrativa oferece uma gama de oportunidades criativas e uma perspectiva de retorno do público que são únicas no meio televisivo. Ela deve ser estudada e entendida como um passo chave na história das formas narrativas televisivas. (2012, p. 31)

Dunleavy (2018) também aponta para a necessidade de a narrativa ser concebida como serial para que tenha potencial de desenvolver uma estória sofisticada e intrincada. Enquanto o formato episódico ou procedimental encurta os arcos narrativos, o serial os alonga dando mais possibilidades aos roteiristas. Ela também identifica num conjunto de séries, que inclui The Sopranos, Mad Men, Breaking Bad, Six Feet Under, The Wire, Oz, Boardwalk Empire, Dexter, True Blood e Stranger Things, outras cinco estratégias narrativas que estão presentes nas séries classificadas como complexas: originalidade conceitual, isto é, exploração de temas inéditos na ficção televisiva a partir de um ponto de vista particular; integração de forma inusitada dos dilemas do personagem central nos arcos da narrativa; desenvolvimento de personagens centrais em conflito moral com potencial para transgressões criminais, mas que não sejam tão anormais a ponto de a audiência rejeitá-los; inclusão de flashbacks e/ou flash-forwards, que adicionem informações para compreensão dos personagens no presente diegético; e investigação psicológica aprofundada dos personagens transgressores ou perturbados, destacando seus problemas e progressos.

As estratégias operam, conforme demonstra Dunleavy (2018), de forma interdependente nas séries e contribuem para torná-las intrincadas. Quando são eficazes, essas estratégias tornam as narrativas atraentes a segmentos da audiência que lhes conferem prestígio, como os críticos e parte dos assinantes dos canais pagos.

Os artifícios que dão complexidade às narrativas não são, no entanto, a fórmula de sucesso no âmbito da criação. A qualidade e o sucesso de uma série televisiva são o resultado de uma complexa combinação de múltiplos fatores que estão além do roteiro. Entre eles, vale destacar, por exemplo, a qualidade do elenco, que pode potencializar ou enfraquecer os atributos do script, mesmo quando este recorre a estratégias que criem narrativas mais desafiadoras à audiência. 
Para verificar o impacto do fenômeno de complexificação das narrativas e de outros elementos associados à produção, gêneros e formatos nas preferências do público e da crítica, busca-se identificar a seguir as principais macrocaracterísticas que as séries mais premiadas e de maior audiência apresentam a partir dos anos 2000.

\section{Características mais frequentes nas séries bem-sucedidas}

Entre 2001 e 2017, um conjunto de produções dramáticas elevou o status quo das séries televisivas. Dentre elas, destacam-se aquelas agraciadas com as mais importantes premiações da televisão, como os prêmios Emmy, Emmy Internacional e Globo de Ouro. O levantamento a seguir (Quadro 1) traz as características mais frequentes nas séries mais premiadas e populares, especialmente nos Estados Unidos - dado ser o maior e mais influente mercado da indústria do audiovisual ${ }^{6}$-, mas abarca também as de outros países, incluindo o Brasil.

Os dados evidenciam algumas diferenças significativas entre as preferências da crítica especializada e do público em geral.

No âmbito da crítica: entre 2001 e 2017, quinze produções norteamericanas venceram as categorias de melhor série dramática (Quadro 1) do Emmy (Primetime Emmy Award for Outstanding Drama Series) e do Globo de Ouro (Best Televison Series - Drama); e quatorze produções, oriundas principalmente do Reino Unido, Dinamarca e França, venceram a categoria de melhor série dramática do prêmio Emmy Internacional, entre $2002^{7}$ e 2017 (Quadro 2).

Quadro 1: Séries dramáticas mais premiadas nos EUA (2001-2017)

\begin{tabular}{|c|c|c|c|c|}
\hline Série & Emmy & Globo de Ouro & Produtora & Temporadas \\
\hline Six Feet Under & 0 & 1 & HBO & $2001-2005$ \\
\hline 24 & 1 & 1 & FOX & $2001-2010$ \\
\hline The Shield & 0 & 1 & FX & $2002-2008$ \\
\hline Nip/Tuck & 0 & 1 & FX & $2003-2010$ \\
\hline Lost & 1 & 1 & ABC & $2004-2010$ \\
\hline Grey's Anatomy & 0 & 1 & ABC & 2005 -atual \\
\hline Mad Men & 4 & 3 & AMC & $2007-2015$ \\
\hline Breaking Bad & 2 & 1 & AMC & $2008-2013$ \\
\hline
\end{tabular}

(continua)

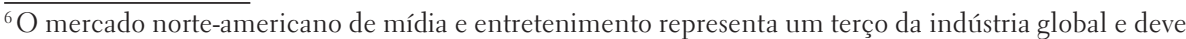
alcançar cerca de US\$ 800 bilhões em receitas em 2019, segundo projeções da PricewaterhouseCoopers (INTERNATIONAL TRADE ADMINISTRATION, 2016, p. 5 ).
}

${ }^{7}$ A categoria de melhor série dramática no International Emmy Award foi criada em 2002. 
Quadro 1: Continuação

\begin{tabular}{|c|c|c|c|c|}
\hline Série & Emmy & Globo de Ouro & Produtora & Temporadas \\
\hline Homeland & 1 & 2 & Showtime & 2011-atual \\
\hline Game of Thrones & 2 & 0 & HBO & 2011-atual \\
\hline Boardwalk Empire & 0 & 1 & HBO & 2010 -2014 \\
\hline Mr. Robot & 0 & 1 & USA Network & 2015-atual \\
\hline The Crown & 0 & 1 & Netflix & 2016-atual \\
\hline The Affair & 0 & 1 & Showtime & 2014-atual \\
\hline The Handmaid's Tale & 1 & 1 & Hulu & 2017-atual \\
\hline
\end{tabular}

Fonte: Television Academy e Hollywood Foreigner Press Association.

Quadro 2: Vencedoras do prêmio Emmy Internacional (2002-2017) ${ }^{8}$

\begin{tabular}{|c|c|c|c|}
\hline Série & Prêmios recebidos & Produtora & País \\
\hline Rejseholdet & 1 & Danmarks Radio & Dinamarca \\
\hline Nikolaj og Julie & 1 & Danmarks Radio & Dinamarca \\
\hline Waking the Dead & 1 & BBC & Reino Unido \\
\hline The Eagle & 1 & Danmarks Radio & Dinamarca \\
\hline Life on Mars & 2 & Kudos & Reino Unido \\
\hline The Street & 2 & BBC & Reino Unido \\
\hline The Protectors & 1 & Danmarks Radio & Dinamarca \\
\hline Accused & 1 & BBC & Reino Unido \\
\hline Braquo & 1 & Capa Drama & França \\
\hline Les Revenants & 1 & Haut et Court & França \\
\hline Utopia & 1 & Kudos & Reino Unido \\
\hline Spiral & 1 & Canal + & França \\
\hline Deutschland 83 & 1 & RTL Television/UFA Fiction & Alemanha \\
\hline Mammon & 1 & NRK Drama/SVT/DR/YLE FEM & Noruega \\
\hline
\end{tabular}

Fonte: International Academy of Television Arts \& Sciences (IATAS).

Essas séries têm como macrocaracterísticas comuns:

- serem majoritariamente produzidas por canais por assinatura nos Estados Unidos e pela TV pública na Europa: 80\% das séries vencedoras nas categorias de melhor série dramática foram produzidas pelos canais por assinatura nos Estados Unidos, enquanto apenas 20\% foram pelos canais

\footnotetext{
$\overline{{ }^{8} \text { No período de } 2011}$ a 2017, cinco séries brasileiras foram indicadas ao prêmio Emmy Internacional na categoria melhor série dramática: Mandrake (HBO Brasil), com indicações em 2006, 2007 e 2008; Na Forma da Lei (Rede Globo), em 2011; O Brado Retumbante (Rede Globo), em 2013; Psi (HBO Brasil), em 2015; e Justiça (Rede Globo), em 2017. As principais características comuns a elas são: um canal da TV aberta (Rede Globo) e um da TV por assinatura (HBO Brasil) aparecem como principais produtores, todas adotam o formato serial e trazem abordagens que mimetizam a realidade.
} 
abertos ${ }^{9}$. Tal resultado mostra uma mudança significativa em relação às décadas anteriores, quando havia o amplo predomínio dos canais abertos (ver ANAZ, 2018); na Europa, prevalecem as produções (60\%) para canais abertos desenvolvidas por e para redes de tevê públicas, como a BBC (Reino Unido) e a Danmarks Radio (Dinamarca);

- apresentarem formato serial: nos Estados Unidos, com exceção de Grey's Anatomy e Nip/Tuck, que são séries procedimentais, isto é, com episódios autoconclusivos, independentes e que repetem o mesmo padrão narrativo a cada episódio, as demais são serializadas. Essa prevalência do formato serial também acontece na produção europeia, principalmente na década de $2010^{10}$;

- prevalência do realismo ${ }^{11}$ : as séries com abordagens que mimetizam a realidade predominam no gosto da crítica, representando $80 \%$ dos títulos premiados; e

- uso de estratégias narrativas que complexificam o conteúdo: com exceção das séries procedimentais e/ou episódicas (Nip/Tuck, Grey's Anatomy, Rejseholdet, Waking the Dead, The Eagle e Accused), as demais recorrem ao conjunto de estratégias narrativas descritas por Mittell (2012, 2015) e Dunleavy (2018) para compor estórias intrincadas.

No âmbito das preferências do público, há algumas diferenças importantes em relação às escolhas da crítica.

No caso de números absolutos de audiência na TV americana (Quadro 3), há predomínio do formato procedimental e dos dramas criminais: as séries CSI (CBS) e NCIS (CBS) foram as mais assistidas em 15 das 17 temporadas. A única produção serial e de canais fechados que figura entre as mais populares é The Walking Dead (AMC), sendo a segunda mais assistida nas temporadas 2013-2014 e 2015-2016, e a terceira em 2012-2013.

\footnotetext{
${ }^{9}$ Canais por assinatura: HBO, FX, AMC, Showtime, USA Network, Netflix e Hulu. Canais abertos: Fox e $\mathrm{ABC}$.

${ }^{10}$ Rejseholdet, Waking the Dead, The Eagle, Life on Mars e Accused são episódicas/procedimentais. As demais são seriais.

${ }^{11}$ No grupo das séries consideradas realistas estão: Six Feet Under, 24 Horas, The Shield, Nip/Tuck, Grey's Anatomy, Mad Men, Breaking Bad, Homeland, Boardwalk Empire, The Crown e The Affair, nos Estados Unidos, e Rejseholdet, Nikolaj og Julie, Waking the Dead, The Eagle, The Street, The Protectors, Accused, Braquo, Les Revenants, Utopia, Spiral, Deutschland 83 e Mammon, na Europa. No grupo de séries não realistas estão: Lost, Game of Thrones, Mr. Robot e The Handmaid's Tale, nos Estados Unidos, e Life on Mars, na Europa.
} 
Quadro 3: Séries com maior audiência nos EUA (2001-2017)

\begin{tabular}{|c|c|c|c|c|c|}
\hline Temporada & Mais assistida & $\begin{array}{l}\text { 2a. mais } \\
\text { assistida }\end{array}$ & $\begin{array}{l}\text { 3a. mais } \\
\text { assistida }\end{array}$ & $\begin{array}{l}\text { 4a. mais } \\
\text { assistida }\end{array}$ & $\begin{array}{l}\text { 5a. mais } \\
\text { assistida }\end{array}$ \\
\hline $2000-2001$ & $\mathrm{ER}(\mathrm{NBC})$ & $\begin{array}{l}\text { Law\&Order } \\
\text { (NBC) }\end{array}$ & $\begin{array}{l}\text { The Practice } \\
\text { (ABC) }\end{array}$ & CSI (CBS) & $\begin{array}{c}\text { The West Wing } \\
\text { (NBC) }\end{array}$ \\
\hline $2001-2002$ & CSI (CBS) & $\mathrm{ER}(\mathrm{NBC})$ & $\begin{array}{l}\text { Law\&Order } \\
\text { (NBC) }\end{array}$ & $\begin{array}{c}\text { The West Wing } \\
\text { (NBC) }\end{array}$ & $\begin{array}{l}\text { Law\&Order: } \\
\text { SVU (NBC) }\end{array}$ \\
\hline $2002-2003$ & CSI (CBS) & $\mathrm{ER}(\mathrm{NBC})$ & $\begin{array}{l}\text { Law\&Order } \\
\text { (NBC) }\end{array}$ & $\begin{array}{l}\text { CSI:Miami } \\
\text { (CBS) }\end{array}$ & $\begin{array}{l}\text { Law\&Order: } \\
\text { SVU (NBC) }\end{array}$ \\
\hline 2003-2004 & CSI (CBS) & $\begin{array}{l}\text { CSI:Miami } \\
\text { (CBS) }\end{array}$ & $\mathrm{ER}(\mathrm{NBC})$ & $\begin{array}{l}\text { Without a Trace } \\
\text { (CBS) }\end{array}$ & $\begin{array}{l}\text { Law\&Order } \\
\text { (NBC) }\end{array}$ \\
\hline $2004-2005$ & CSI (CBS) & $\begin{array}{c}\text { Desperate } \\
\text { Housewives } \\
(\mathrm{ABC})\end{array}$ & $\begin{array}{l}\text { CSI:Miami } \\
\text { (CBS) }\end{array}$ & $\begin{array}{c}\text { Without a Trace } \\
\text { (CBS) }\end{array}$ & $\begin{array}{c}\text { Grey's Anatomy } \\
\text { (ABC) }\end{array}$ \\
\hline $2005-2006$ & CSI (CBS) & $\begin{array}{c}\text { Desperate } \\
\text { Housewives } \\
(\mathrm{ABC})\end{array}$ & $\begin{array}{l}\text { Grey's Anatomy } \\
\text { (ABC) }\end{array}$ & $\begin{array}{l}\text { Without a Trace } \\
\text { (CBS) }\end{array}$ & $\begin{array}{l}\text { CSI:Miami } \\
\text { (CBS) }\end{array}$ \\
\hline 2006-2007 & CSI (CBS) & $\begin{array}{l}\text { Grey's Anatomy } \\
\text { (ABC) }\end{array}$ & House (FOX) & $\begin{array}{c}\text { Desperate } \\
\text { Housewives } \\
(\mathrm{ABC})\end{array}$ & $\begin{array}{l}\text { CSI:Miami } \\
\text { (CBS) }\end{array}$ \\
\hline $2007-2008$ & $\begin{array}{c}\text { Desperate } \\
\text { Housewives } \\
(\mathrm{ABC})\end{array}$ & CSI (CBS) & House (FOX) & $\begin{array}{l}\text { Grey's Anatomy } \\
\text { (ABC) }\end{array}$ & $\begin{array}{l}\text { CSI:Miami } \\
\text { (CBS) }\end{array}$ \\
\hline 2008-2009 & CSI (CBS) & NCIS (CBS) & $\begin{array}{l}\text { The Mentalist } \\
\text { (CBS) }\end{array}$ & $\begin{array}{c}\text { Desperate } \\
\text { Housewives } \\
(\mathrm{ABC})\end{array}$ & $\begin{array}{l}\text { Grey's Anatomy } \\
\text { (ABC) }\end{array}$ \\
\hline 2009-2010 & NCIS (CBS) & $\begin{array}{l}\text { The Mentalist } \\
\text { (CBS) }\end{array}$ & $\begin{array}{c}\text { NCIS:Los } \\
\text { Angeles (CBS) }\end{array}$ & CSI (CBS) & $\begin{array}{c}\text { Grey's Anatomy } \\
\text { (ABC) }\end{array}$ \\
\hline $2010-2011$ & NCIS (CBS) & $\begin{array}{c}\text { NCIS: Los } \\
\text { Angeles (CBS) }\end{array}$ & $\begin{array}{l}\text { The Mentalist } \\
\text { (CBS) }\end{array}$ & $\begin{array}{l}\text { Body of Proof } \\
\text { (ABC) }\end{array}$ & $\begin{array}{l}\text { Criminal Minds } \\
(\mathrm{CBS})\end{array}$ \\
\hline $2011-2012$ & NCIS (CBS) & $\begin{array}{c}\text { NCIS: Los } \\
\text { Angeles (CBS) }\end{array}$ & $\begin{array}{l}\text { The Mentalist } \\
\text { (CBS) }\end{array}$ & $\begin{array}{c}\text { Person of } \\
\text { Interest (CBS) }\end{array}$ & $\begin{array}{l}\text { Criminal Minds } \\
\text { (CBS) }\end{array}$ \\
\hline $2012-2013$ & NCIS (CBS) & $\begin{array}{c}\text { NCIS: Los } \\
\text { Angeles (CBS) }\end{array}$ & $\begin{array}{c}\text { Person of } \\
\text { Interest (CBS) }\end{array}$ & $\begin{array}{l}\text { The Walking } \\
\text { Dead (AMC) }\end{array}$ & $\begin{array}{l}\text { Blue Bloods } \\
\quad \text { (CBS) }\end{array}$ \\
\hline $2013-2014$ & NCIS (CBS) & $\begin{array}{l}\text { The Walking } \\
\text { Dead (AMC) }\end{array}$ & $\begin{array}{c}\text { NCIS:Los } \\
\text { Angeles (CBS) }\end{array}$ & $\begin{array}{l}\text { The Blacklist } \\
\text { (NBC) }\end{array}$ & $\begin{array}{c}\text { Person of } \\
\text { Interest }(\mathrm{CBS})\end{array}$ \\
\hline $2014-2015$ & NCIS (CBS) & $\begin{array}{l}\text { NCIS:New } \\
\text { Oleans (CBS) }\end{array}$ & $\begin{array}{l}\text { Empire } \\
(\mathrm{FOX})\end{array}$ & $\begin{array}{l}\text { Criminal Minds } \\
\text { (CBS) }\end{array}$ & $\begin{array}{l}\text { Blue Bloods } \\
\text { (CBS) }\end{array}$ \\
\hline $2015-2016$ & NCIS (CBS) & $\begin{array}{l}\text { The Walking } \\
\text { Dead (AMC) }\end{array}$ & Empire (FOX) & $\begin{array}{l}\text { NCIS:New } \\
\text { Oleans (CBS) }\end{array}$ & $\begin{array}{l}\text { Blue Bloods } \\
\qquad(\mathrm{CBS})\end{array}$ \\
\hline 2016-2017 & NCIS (CBS) & Bull (CBS) & $\begin{array}{c}\text { NCIS:Los } \\
\text { Angeles (CBS) }\end{array}$ & $\begin{array}{l}\text { Blue Bloods } \\
\quad(\mathrm{CBS})\end{array}$ & $\begin{array}{l}\text { This is Us } \\
\text { (NBC) }\end{array}$ \\
\hline
\end{tabular}

Fonte: Nielsen. 
Nessa situação, há significativas diferenças entre o gosto do púbico e o da crítica, conforme representado na Figura 3. Aqui, no entanto, é preciso ponderar o peso da questão econômica nos resultados das séries mais assistidas, uma vez que as produções veiculadas nos canais abertos são mais acessíveis a todos os segmentos da população do que as transmitidas pelos canais por assinatura.
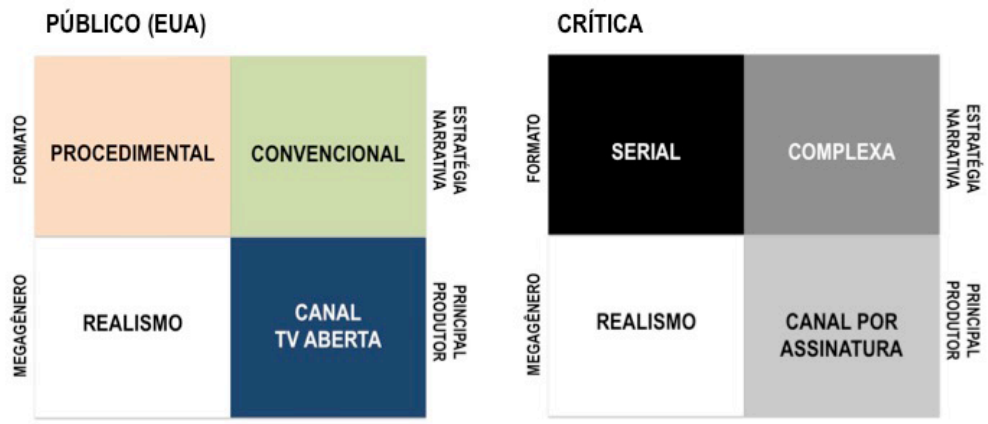

Figura 3: Principais características das séries preferidas pelo público (EUA) e pela crítica Fonte: Elaborado pelo autor.

Mas, se ampliarmos a amostragem para além dos Estados Unidos e para um universo no qual essa questão de acesso econômico aos programas esteja atenuada, os resultados da preferência de público mudam.

A mensuração da demanda por expressão ${ }^{12}$ em relação aos programas televisivos, desenvolvida pela Parrot Analytics, ainda que abranja um período curto (e faça, portanto, um retrato muito imediato dessas preferências), mostra quais são as séries dramáticas com maior demanda em multiplataformas no mercado global (Quadro 4).

Quadro 4: Séries dramáticas com maior expressão de demanda global

\begin{tabular}{|c|c|c|c|c|c|}
\hline Temporada & $\begin{array}{c}\text { Mais } \\
\text { assistida }\end{array}$ & $\begin{array}{c}2^{\mathrm{a}} \text { mais } \\
\text { assistida }\end{array}$ & $\begin{array}{c}3^{\mathrm{a}} \text { mais } \\
\text { assistida }\end{array}$ & $\begin{array}{c}4^{\mathrm{a}} \text { mais } \\
\text { assistida }\end{array}$ & $\begin{array}{c}5^{\mathrm{a}} \text { mais } \\
\text { assistida }\end{array}$ \\
\hline 2016 & $\begin{array}{c}\text { Game of } \\
\text { Thrones (HBO) }\end{array}$ & $\begin{array}{c}\text { The Walking } \\
\text { Dead (AMC) }\end{array}$ & $\begin{array}{c}\text { Pretty Little } \\
\text { Liars (Freeform) }\end{array}$ & $\begin{array}{c}\text { Westworld } \\
\text { (HBO) }\end{array}$ & $\begin{array}{c}\text { The Flash } \\
(\mathrm{CW})\end{array}$ \\
\hline 2017 & $\begin{array}{c}\text { Game of } \\
\text { Thrones (HBO) }\end{array}$ & $\begin{array}{c}\text { The Walking } \\
\text { Dead (AMC) }\end{array}$ & $\begin{array}{c}\text { Pretty Little } \\
\text { Liars (Freeform) }\end{array}$ & $\begin{array}{c}\text { Prison Break } \\
\text { (FOX) }\end{array}$ & $\begin{array}{c}\text { Vikings } \\
\text { (History) }\end{array}$ \\
\hline
\end{tabular}

Fonte: Business Insider/Insider (LUBIN, 2016; NEDEDOG, 2017).

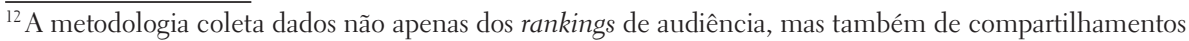
(peer-to-peer) via Internet, das mídias sociais e de outras plataformas e dispositivos que permitem estimar a demanda pelos programas televisivos no âmbito global.
} 
As principais características comuns a essas séries são:

- canais por assinatura predominam como produtores: $80 \%$ das séries dramáticas mais assistidas em multiplataformas foram produzidas por eles ${ }^{13}$;

- formato serial: todas as narrativas são serializadas, sendo que The Flash (CW) apresenta um formato híbrido (serial e episódico);

- ficção científica e fantasia prevalecem como gênero: 60\% dos títulos (Game of Thrones, The Walkind Dead, The Flash e Westworld) exploram esses gêneros; e

- uso de estratégias narrativas que complexificam o conteúdo: as séries recorrem à maioria das estratégias elencadas por Dunleavy (2018).

Nesse contexto, há entre o gosto da crítica (Quadros 1 e 2) e o da audiência global (Quadro 4) uma convergência em relação à preferência por séries produzidas pelos canais por assinatura, pelo formato serial e por aquelas que recorrem a estratégias narrativas para torná-las complexas. Mas há também uma diferença em relação ao gênero favorito: enquanto a crítica prefere narrativas realistas, o público prefere as não realistas (ficção científica e fantasia). A Figura 4 sintetiza essa comparação entre as preferências.

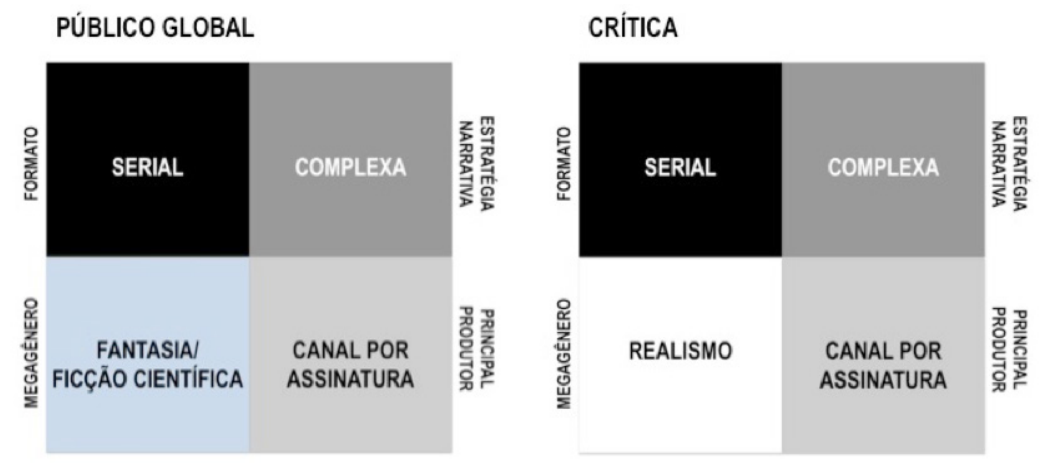

Figura 4: Principais características das séries preferidas pela audiência global e pela crítica Fonte: Elaborado pelo autor.

Uma das principais consequências do predomínio dessas macrocaracterísticas das séries dramáticas - formato serial, complexidade narrativa e produção pelos canais por assinatura - é a consolidação de um novo patamar de comportamento ativo e engajamento da audiência em relação aos temas e desafios colocados pelas narrativas.

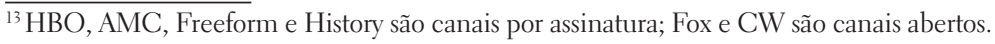




\section{A questão do engajamento da audiência}

Como vimos, o predomínio da serialização sobre o formato procedimental possibilita a continuidade das tramas por vários episódios e temporadas, permitindo, no plano da criação, o desenvolvimento de arcos longos e a elaboração de personagens e enredos mais densos, além da exploração de recursos narrativos não convencionais. Esse atributo também potencializa, no âmbito da fruição, maior grau de engajamento dos espectadores no desvelamento do que há de mais intrincado nas estórias.

A questão do engajamento da audiência constitui-se em um dos principais diferenciais das séries dramáticas bem-sucedidas, na medida em que significa não só esforços cognitivos acima da média por parte do espectador para a compreensão da narrativa, mas também atitudes ativas por parte dele em relação à série, como participação em grupos de discussão, pesquisas de informações e colaboração em enciclopédias virtuais (wikis), por exemplo. Tal ação pode resultar na produção de expressivas quantidades de informações e conhecimentos em rede pela (e para a) audiência.

Analisado por Jenkins (2008) e Levy (2007), o ativismo e engajamento da audiência caracteriza-se principalmente pela colaboração coletiva entre os fãs dos produtos culturais alavancada pelas tecnologias digitais da comunicação e pela constituição do ciberespaço. Dois conceitos centrais nessa perspectiva são o da inteligência coletiva, definida como a "capacidade das comunidades virtuais de alavancar a expertise combinada de seus membros" (JENKINS, 2008, p. 54), e o do fandom, comunidade de membros emocionalmente envolvidos no consumo/fruição regular de uma determinada narrativa da cultura popular.

A dimensão alcançada por um fandom pode ser, assim, um dos índices para se mensurar o grau de engajamento e colaboração que uma série dramática estimula em seu público. Baseada nessa possibilidade e consideradas as séries preferidas pela crítica (Quadros 1 e 2) e pelo público (Quadros 3 e 4), é possível verificar quais delas registram maior produção de informações por parte das comunidades de admiradores. Os resultados apresentados no Quadro 5 mostram as dez séries com maiores índices de engajamento dos fãs na construção de enciclopédias virtuais com informações sobre cada uma delas no modelo colaborativo (wiki), ponderando-se o tempo em que estão/ficaram em cartaz.

Entre as dez séries de maior índice de engajamento (Quadro 5), além do predomínio das narrativas no formato serial e de estratégia complexa (80\%) e das produzidas pelos canais por assinatura (70\%), evidencia-se também que tanto 
narrativas com abordagens realistas como as não realistas ${ }^{14}$ têm igual potencial de gerar o envolvimento ativo do espectador.

Quadro 5: Índice de engajamento dos fãs ${ }^{15}$

\begin{tabular}{|c|c|c|c|}
\hline Série & Fandom & Temp. & Índice \\
\hline Lost & 11.905 & 6 & 1.984 \\
\hline NCIS & 19.491 & 15 & 1.299 \\
\hline The Walking Dead & 8.802 & 8 & 1.100 \\
\hline 24 & 8.899 & 9 & 989 \\
\hline Game of Thrones & 5.422 & 7 & 775 \\
\hline The Flash & 2.160 & 4 & 540 \\
\hline Grey's Anatomy & 7.248 & 14 & 518 \\
\hline Prison Break & 2.244 & 5 & 449 \\
\hline Boardwalk Empire & 1.820 & 5 & 364 \\
\hline Westworld & 323 & 1 & 323 \\
\hline
\end{tabular}

Fontes: Fandom/Wikia/IMDb.

Apesar disso, é notório o destaque que a série Lost, que mistura ficção científica e fantasia, tem nesse atributo. Seu elevado índice de engajamento pode ser o resultado de dois recursos narrativos adotados por seus criadores: múltiplo protagonismo (com perspectivas distintas) ${ }^{16}$ e concepções espaço-temporais não convencionais ${ }^{17}$. Esses atributos também aparecem em outras narrativas dentre aquelas com engajamento mais elevado. São os casos das séries 24 Horas e Westworld, que trabalham com concepções temporais não convencionais - em 24 Horas, a ação se dá equiparando-se o tempo diegético ao tempo real do espectador e, em Westworld, “as tramas desenvolvem-se em duas linhas temporais (passado e presente) que são apresentadas simultaneamente ao espectador, sendo que cada uma delas contém ainda dois tipos de temporalidades operando de forma entrelaçada em seu interior:

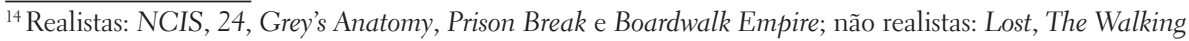
Dead, Game of Thrones, The Flash e Westworld.

${ }^{15} \mathrm{O}$ cálculo do índice de engajamento foi feito considerando o número de páginas que compunham os Fandom/Wikis de cada uma das séries divididas pelo número de temporadas que a série ficou/está em cartaz, em 31 de janeiro de 2018. Em alguns casos, como em Lost, The Walking Dead e Game of Thrones, há mais de um wiki desenvolvido pelos fãs.

${ }^{16}$ Deve-se ressaltar que não se trata aqui de uma polifonia, no sentido elaborado por Bakhtin, ao analisar a obra de Dostoiévsky (no livro Problemas da poética de Dostoiévsky), pois tais perspectivas múltiplas e distintas não são necessariamente divergentes no âmbito ideológico ou de visão de mundo.

${ }^{17}$ Concepções que apresentam temporalidades não lineares e progressivas e/ou espacialidades multidimensionais.
} 
o tempo circular, dos androides, e o linear, dos humanos" (ANAZ, 2018) -, e Game of Thrones, cujas tramas são contadas a partir das múltiplas perspectivas de mais de uma dezena de protagonistas. Tais resultados indicam o quanto o uso de concepções espaço-temporais não convencionais e múltiplos pontos de vista são recursos narrativos eficazes para tornar as tramas desafiadoras à audiência.

Mas o engajamento da audiência, além de ser resultado do estímulo aos espectadores para resolverem quebra-cabeças propostos nas tramas, é fruto também das entrelinhas que as narrativas deixam para que a imaginação do espectador complemente, intertextualize e amplifique o que está colocado nas tramas.

Ricoeur (1990, p. 56) observou que no processo de interpretação o ser projeta-se no mundo proposto pela obra: "o que deve ser interpretado, num texto, é uma proposição de mundo, de um mundo tal como posso habitá-lo para nele projetar um de meus possíveis [possibilidades de ser-no-mundo] mais próprios". Nesse processo de fruição, a imaginação exerce um papel fundamental. Como destaca Almeida (2016, p. 204), "não somente o criador imagina sua obra quando a cria, mas também o leitor e o espectador, que empreendem esforços perceptivos, imaginativos e cognitivos para construir a história que está lendo/assistindo”.

A potencialidade do engajamento está relacionada, assim, aos espaços deixados, possibilidades criadas e estímulos presentes na narrativa para que a imaginação da audiência atue de forma a suplementar, ampliar e revelar o mundo diegético incompreendido ${ }^{18}$.

Nesse aspecto, uma das estratégias mais frequentes para estimular a atuação da imaginação da audiência, evidenciada pelas séries dramáticas com maior índice de engajamento (Quadro 5), é a associação entre mistérios e conspirações (ou suspeitas de conspirações). Tal associação é ostensiva em Lost, 24 Horas, Game of Thrones, The Walking Dead, Prison Break, The Flash e Westworld.

O que se observa é que a maioria das séries televisivas com maior índice de engajamento reproduz um fenômeno presente no cinema desde os anos 1970, com o constante sucesso de público e/ou de crítica de narrativas conspiratórias, como Três Dias do Condor (1975), de Sydney Pollack, a trilogia Matrix (1999-2003), das

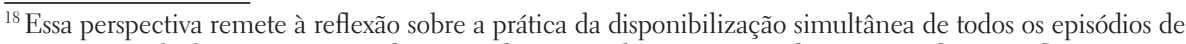
uma temporada das séries, principalmente pelos canais de streaming. Tal prática arrefece significativamente o engajamento da audiência, quando não o elimina completamente, na chamada atitude de binge-watching. Séries de sucesso que tiveram seus episódios disponibilizados dessa forma apresentam baixíssimo índice de engajamento. São os casos de: Stranger Things (132), House of Cards (85) e Black Mirror (35), por exemplo, cujos índices de engajamento apresentados entre parênteses (calculado pelos mesmos critérios adotados no Quadro 5) são muito inferiores aos das séries com exibição de um episódio por semana.
} 
The Wachowskis, e A Origem (2010), de Christopher Nolan, entre outras. Trifonova (2017) aponta que a rotinização da conspiração no cinema, a partir da década de 1970, tem como marca a mudança de foco da paranoia individual para a institucional (governos, organismos internacionais e multilaterais, corporações etc.) e torna-se um mapa cognitivo simplificador com o qual o espectador tenta enfrentar um mundo crescentemente complexo.

Assim, boa parte das séries dramáticas contemporâneas com complexidade narrativa e bem-sucedidas, embora adensem e problematizem tramas e personagens afastando-se muitas vezes da estereotipia e dando-lhes características arquetípicas, no sentido junguiano -, ainda tem na exploração das teorias de conspirações institucionais (sejam elas efetivadas ou apenas sugeridas) um dos principais elementos para promover o engajamento da audiência.

\section{Conclusões}

Ao longo desta investigação, foi possível observar que há objetivamente uma série de atributos que distingue um conjunto de séries dramáticas contemporâneas bem-sucedidas a partir do público e da crítica. Esses atributos são o resultado de transformações em diferentes âmbitos, conforme já havia apontado Mittell (2015): nas tecnologias de comunicação, no comportamento da audiência, nas estratégias de negócios, no formato das séries e no uso de efeitos especiais narrativos.

Dada a amplitude dessas transformações, o estudo do fenômeno demandou uma análise transversal do processo, indo da criação/produção à fruição/consumo, uma vez que essas duas pontas alimentam as características principais das narrativas televisivas. Nesse aspecto, identificar particularidades dos processos de criação e fruição das séries dramáticas nos anos 2000 foi fundamental como ponto de partida para demonstrar a importância que alguns fatores têm na configuração dessas narrativas. Entre esses fatores estão: o formato serial, que permite um tempo narrativo estendido, possibilitando adensar tramas e personagens, com o aprofundamento das características psicológicas dos personagens e a problematização das intrigas; o papel do showrunner, que dá ao criador da série uma maior autonomia e autoridade ao longo dos processos de criação, produção e tomada de decisões corporativas, que envolvem criadores e executivos da produtora (e/ou estúdio) e da emissora; e fruição concorrida e complementar das narrativas, uma vez que a ambientação pode levar a um grau elevado de distração da audiência, enquanto o uso de múltiplas telas possibilita ao telespectador ampliar o universo informacional sobre a narrativa. 
Estabelecido esse contexto, buscou-se identificar quais seriam os atributos mais frequentes presentes nas séries mais premiadas pela crítica e de maior audiência. A análise concentrou-se em quatro macroaspectos: formato (serial, híbrido ou procedimental/episódico), estratégia narrativa (complexa ou convencional), produtor (canal por assinatura ou canal de TV aberto) e megagênero (realista ou não realista). Um dos achados mais importantes da análise foi identificar, quando o acesso aos produtos dos canais pagos não se constitui num entrave econômico, a convergência nos gostos da crítica e do público em relação à preferência por séries produzidas pelos canais por assinatura, pelo formato serial e por estórias que recorrem a estratégias narrativas para torná-las complexas. Em relação ao megagênero preferido, foi observado que, enquanto a crítica prefere narrativas realistas, o público prefere as não realistas (ficção científica e fantasia).

Tais características aliadas a determinados recursos narrativos têm estimulado maior grau de engajamento e de atitudes ativas da audiência em relação aos temas e desafios colocados pelas narrativas. Entre os principais recursos narrativos utilizados nesse sentido estão as concepções espaço-temporais não convencionais, os múltiplos pontos de vista e a profusão de teorias conspiratórias institucionais, utilizados pelos roteiristas para criar tramas desafiadoras. Nesse aspecto, pode-se observar que a potencialidade do engajamento está correlacionada à polissemia da narrativa (e não necessariamente a conteúdos sofisticados), isto é, à abertura de sentidos que permite à imaginação do espectador suplementar, ampliar e revelar o mundo diegético.

À medida que as séries dramáticas produzidas para a TV se constituem em um dos mais importantes fenômenos comunicacionais contemporâneos, espera-se que os atributos aqui mapeados possam contribuir para o aprofundamento dos estudos e da discussão desse fenômeno.

\section{Referências}

ALMEIDA, R. "O processo de criação literária pensado pelo cinema de François Ozon: análise de dois filmes”. In: LEÃO, L. (Org.). Processos do imaginário. São Paulo: Képos, 2016.

ANAZ, S. "Construindo séries de TV complexas: a concepção diegética de Westworld”. Revista Famecos, Porto Alegre, v. 25, n. 2, p. 1-17, 2018. Disponível em: $<$ https://bit.ly/2slKyZ4>. Acesso em: 23 maio 2018.

DUNLEAVY, T. Complex serial drama and multiplataform television. [e-book]. New York: Routledge, 2018. 
INTERNATIONAL TRADE ADMINISTRATION. 2016 Top markets report media and entertainment. Washington, 2016.

JENKINS, H. Cultura da Convergência. São Paulo: Aleph, 2008.

KALLAS, C. Na sala de roteiristas. Rio de Janeiro: Zahar, 2016.

LÉVY, P. A inteligência coletiva: por uma antropologia do ciberespaço. São Paulo: Loyola, 2007.

LUBIN, G. "Data reveals the 20 most popular TV shows of 2016". Business Insider, New York, 30 dez. 2016. Disponível em: <https://read.bi/2LnIBh>. Acesso em: 10 jan. 2018.

MITTELL, J. "Complexidade narrativa na televisão americana contemporânea". Matrizes, São Paulo, v. 5, n. 2, p. 29-52, 2012. Disponível em: <https://bit.ly/2ILlITt >. Acesso em: 23 maio 2018.

Complex TV: the poetics of contemporary television storytelling. New York: New York University Press, 2015.

NEDEDOG, J. "20 most popular TV shows of 2017 so far". Insider, New York, 4 ago. 2017. Disponível em: <https://bit.ly/2klvYrh>. Acesso em: 10 jan. 2018.

RICOEUR, P. Interpretação e ideologias. Rio de Janeiro: F. Alves, 1990.

TRIFONOVA, T. "Agência nos thrillers cinematográficos de conspiração". Rumores, São Paulo, v. 22, n. 11, p. 59-88, 2017. Disponível em: <https://bit.ly/2IZaH4n>. Acesso em: 23 maio 2018.

submetido em: 02 fev. 2018 | aprovado em: 04 maio 2018 